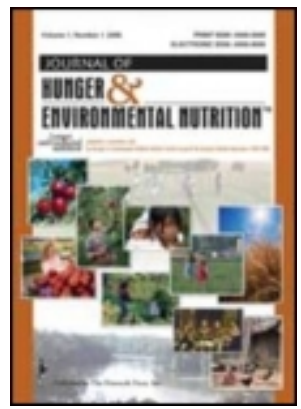

\title{
Perspectives of Environmental Health Promotion and the Mediterranean Diet: A Thematic Narrative Synthesis
}

\begin{tabular}{|r|l|}
\hline Journal: & Journal of Hunger and Environmental Nutrition \\
\hline Manuscript ID & WHEN-2020-0013.R1 \\
\hline Manuscript Type: & Perspectives \\
\hline Keywords: & Mediterranean diet, Environmental Health, Sustainability \\
\hline \multicolumn{2}{|l}{} \\
\end{tabular}

\section{SCHOLARONE ${ }^{m}$ \\ Manuscripts}


Table 1. Environmental health benefits of the MDiet Pattern

\begin{tabular}{|c|c|}
\hline $\begin{array}{l}\text { Increased consumption of: } \\
\text { plant-based Foods } \\
\text { whole grains } \\
\text { legumes } \\
\text { Olive Oil }\end{array}$ & $\begin{array}{l}\text { Emphasis on seasonal and locally } \\
\text { grown/produced items } \\
\text { Decreased reliance on fossil fuels for } \\
\text { processing and distribution }\end{array}$ \\
\hline Decreased red meat intake & $\begin{array}{ll}\text { - } & \text { Reduction of greenhouse gas } \\
\text { emissions } \\
\text { - } \\
\text { - } \\
\text { Lowproved use of arable land } \\
\end{array}$ \\
\hline Decreased processed foods & $\begin{array}{l}\text { - Decreased reliance on fossil fuels for } \\
\text { processing and distribution } \\
\text { - Lower water usage }\end{array}$ \\
\hline Inclusion of fish and seafood & - Emphasis on locally sourced items \\
\hline $\begin{array}{l}\text { Dairy and yogurt consumed daily in low to } \\
\text { moderate amounts }\end{array}$ & $\begin{array}{l}\text { - Reduction of greenhouse gas } \\
\text { emissions } \\
\text { - Improved use of arable land } \\
\text { - Lower water usage }\end{array}$ \\
\hline
\end{tabular}


Figure 1. Environmental impact of MDiet compared to other dietary patterns

a) 60

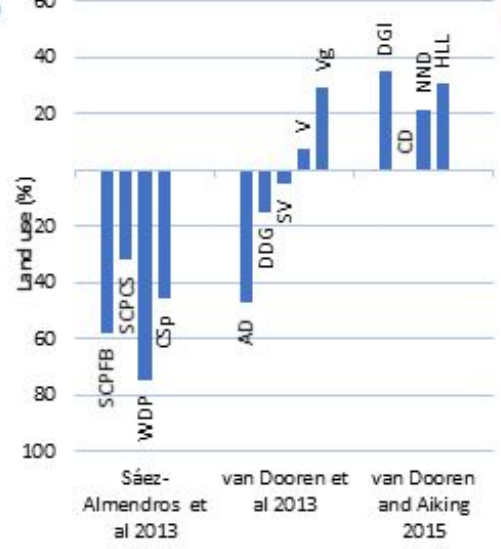

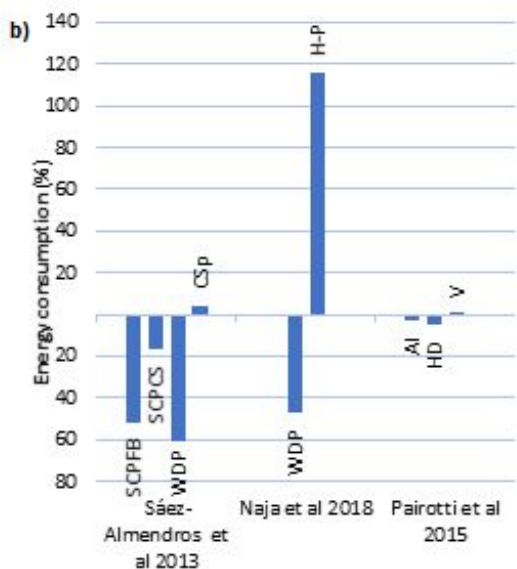

c)

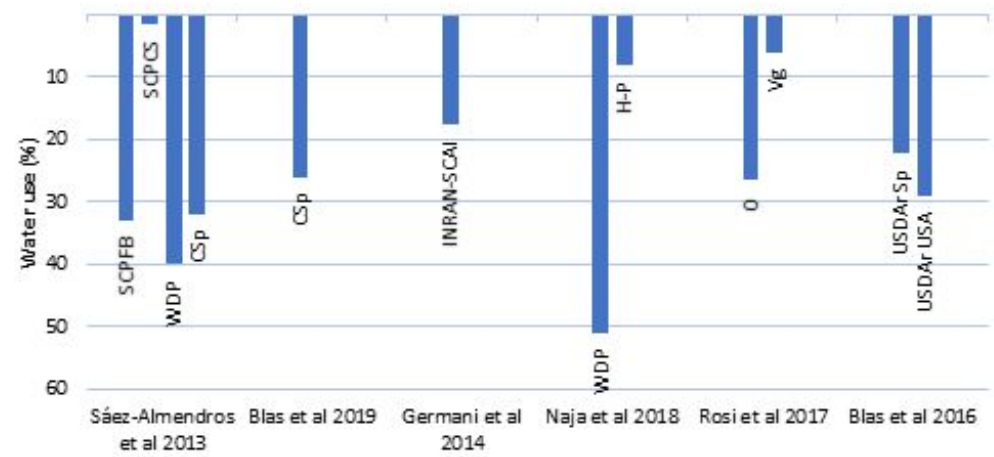

d)
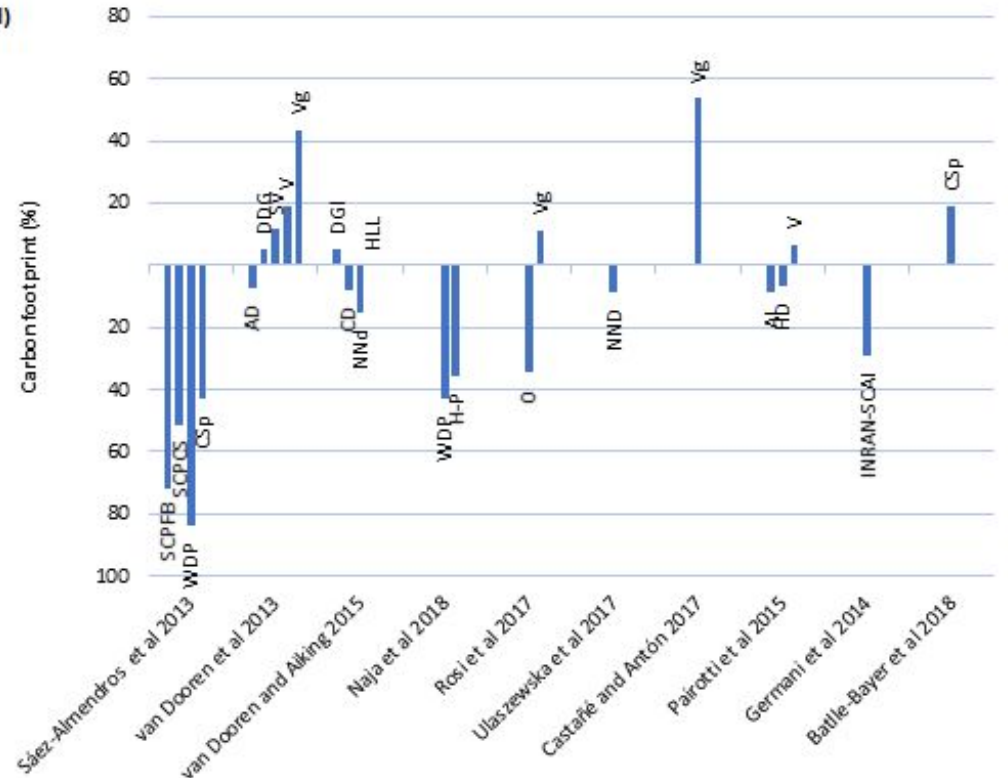

Note* a) land use, b) energy consumption, c) water use, and d) carbon footprint. AD: Average Dutch, AI: Average Italian, CD: Current Dutch, CSp: Current Spanish, DDG: Dutch Dietary Guidelines, DGl: Dietary guidelines, H-P: High-Protein, HD: healthy diet, HLL: Historical Low Lands, INRAN-SCAI: The Italian National Food consumption survey, NND: New Nordic, O: omnivorous, $\mathrm{SCP}_{\mathrm{CS}}$ : the current Spanish dietary pattern estimated from the Household Consumption Surveys of the Spanish Ministry of Agriculture, Food and Environment $\mathrm{SCP}_{\mathrm{FB}}$ : the current Spanish dietary pattern estimated from the FAO food balance sheets, USDAr: The American recommended diet by the US Department of Agriculture, SV: semi vegetarian, V: vegetarian, Vg: vegan, WDP: Western Dietary pattern. 
Figure 2. The Mediterranean Diet and Environmental Health Promotion - A Conceptual Framework

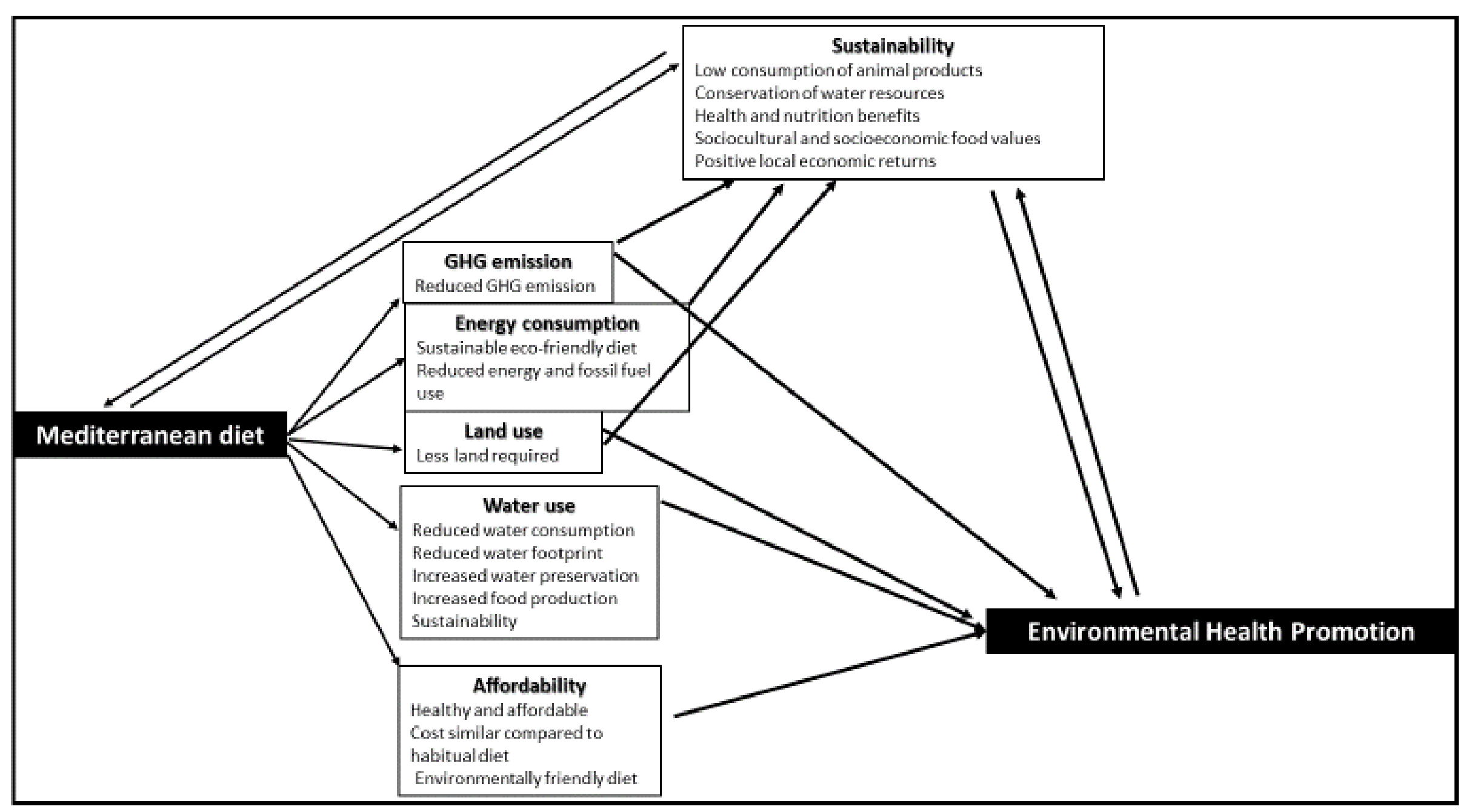


Abstract

A thematic narrative synthesis was conducted to identify literature exploring the Mediterranean Diet (MDiet) and its impact on the environment in terms of land and water use, Greenhouse Gas emissions, fossil fuels, affordability, and acceptability. The MDiet is a sustainable diet that can reduce some environmental impacts of food production while improving both the health of the population and world, diet acceptability, cost, cultural and socio-economic factors should be considered when determining appropriateness of a recommended dietary pattern to a regional or global population.

\section{Key Words}

Mediterranean diet; Environmental health; Sustainability 


\section{Introduction}

Food production places detrimental pressures on the environment by increasing land and water usage, toxic emissions, and climate change. Food production accounts for $19-29 \%$ of Greenhouse gas emissions (GHGE) ${ }^{1}, 70 \%$ of freshwater use ${ }^{2}$, increased eutrophication ${ }^{3}$, and consumption of $35 \%$ of ice-free land 4,5 ; it is also the greatest cause of deforestation and biodiversity loss ${ }^{5}$. However, global dietary patterns govern the production of food. Thus, diet as well as dietary choices and practices affect resource consumption and environmental impact 6,7 . Baroni, et al. ${ }^{8}$ showed that diets with a greater eonsumption content of animal products, compared to diets with a greater consumption of plant products, have a larger influence on the environment, such as increased fossil fuel use, climate change, and ecotoxity. Whereas plantbased diets with high intake of fruits, vegetables, cereals, and legumes have lower GHGE compared to diets with high intake of meat ${ }^{6,7,9}$. A 2005 epidemiological study showed that a $50 \%$ reduction in meat intake, replaced by fruits, vegetables, and grains, related to a $19 \%$ reduction in GHGE and $42 \%$ reduction in land usage in the United Kingdom ${ }^{10}$. Therefore, the production of animal-based products clearly has a large and deleterious role on the environment.

The environmental impact of food production will likely continue to rise as the world population continues to increase and if associated eensequentially as consumption of animal based and processed foods increases. For example, from 1993-2013 population increased by $29 \%$, which correlated to a $62 \%$ increase in demand for animal products ${ }^{11}$. In correspondence with predicted food consumption and population, the United Nations' Food and Agriculture Organization (FAO) projects a 60\% increase in crop and pasture-based food production by 2050

12. Based on such projections, the environmental impact of food production will rise, if the world does not adopt more sustainable dietary habits. 
Sustainable dietary practices refer to diets with low environmental impacts and maintain food and nutritional security and long-term health of a population ${ }^{13-15}$. According to the FAO, "sustainable diets are protective and respectful of biodiversity and ecosystems, culturally acceptable, accessible, economically fair and affordable; nutritionally adequate, safe and healthy; while optimizing natural and human resources" ${ }^{16}$. One diet which reduces consumption of animal products and processed foods is the Mediterranean Diet (MDiet). The MDiet consists of high intake of fruits and vegetables, legumes, oils, and fish, with relatively small amounts of red meat or processed food items ${ }^{17}$. The MDiet focuses on increased intake in plant-based products compared to animal protein and processed foods, reducing environmental impact. Thus, compared to further diet patterns and food production methods, the MDiet has environmentally friendly dietary guidelines and goals to maintain an environmentally sustainable food system. Studies show that the MDiet reduces land usage, GHGE, and global warming compared to meatcentric diets and meat-based food production methods $6,7,10,18$, while reducing risk for cardiovascular and metabolic disease ${ }^{19}$.

Despite the environmental negative consequences of a more Westernized diet, the world population has consistently adopted such dietary patterns when the choice exists; this diet is high in meat products, saturated fats, refined grains, sugar, salt, and as a result, tends to result in reduced consumption of fruits and vegetables ${ }^{20}$. Westernized Diet increases GHGE and use of land, livestock, water, and agrochemicals ${ }^{21}$. Additionally, when compared to MDiet, Westernized Diet increases risks for obesity, cardiovascular disease, and metabolic diseases ${ }^{22}$. Prevalence of these diseases are predicted to rise over the next 30 years, if dietary and lifestyle changes are not made 22,23 . Since Westernized diet Diet directly influences human and environmental health, adoption of the Westernized diet Diet places a great burden on the world 
itself. On the other hand, it appears that the MDiet is a healthful alternative dietary pattern to Westernized diet Điet and could lower detrimental outcomes on the environment through encouraging consumers to consume more plant-based products ${ }^{19,24}$. However, the complete environmental impact of the MDiet is not comprehensively understood. Therefore, this thematic narrative synthesis will identify contemporary literature exploring the MDiet and its impact on the environment in terms of land and water use, GHGE, energy consumption, affordability, and other environmental considerations (see Figure 1).

\author{
Methods \\ A thematic review of the literature was carried out prior to September 2019. No time \\ frame was set during the search in order to obtain a more comprehensive search of relevant \\ published literature data. Articles were identified by applying search strategies to eight academic \\ electronic databases: Scopus, PubMed, SpringerLink, EBSCOhost, SAGE, Wiley Onine, Taylor \\ \& Francis, and ScienceDirect. The Search phrases, terms, and key words included in the final \\ search syntax were "environment; conservation; biodiversity; carbon footprint; water; \\ environmental health; sustainability; climate change; human impact; consumption AND \\ Mediterranean diet; Mediterranean-style diet; Mediterranean dietary pattern”. All retrieved \\ articles were screened for relevance to the topic. Additionally, references from retrieved articles \\ were examined to identify any further additional articles. Grey literature was excluded in this \\ review.
}

\title{
Inclusion and exclusion criteria
}


Footprint measurements and methodology studies, quantitative analyses, cohort studies, communications, commentaries, editorials, brief reports, position, practice, policy, and hypothesis-generating statements, literature reviews, and studies that conducted comparison of the MDiet against other dietary patterns were included. Publications were excluded if publication samples described dietary patterns other than the MDiet. Non-refereed publications also were excluded. Only articles in English were included in the review. Study protocols, grey literature, and conference abstracts were excluded.

\section{Results and Discussion}

According to the FAO, food security exists when all people at all times have physical and economic access to sufficient, safe, and nutritious food to meet their dietary needs and food preferences for an active, healthy life. Sustainable diets are those diets that have low environmental impact and contribute to food and nutrition security and a healthy life for present and future generations 16,25 .

The world population is increasing and requires strategies for a food supply that ensures food security with minimal impacts on our environment. The capacity to produce sufficient quantities of food is potentially limited by water and land use, soil fertility, and conservation of seas and oceans.

The global food production system is responsible for $80 \%$ of deforestation_ ${ }_{-}^{26}$, more than $70 \%$ of freshwater utilization, and up to $30 \%$ of GHGE that have significantly increased_ ${ }_{-}{ }_{-}$over the last 50 years. Additionally, large scale food production has been shown to negatively affect biodiversity ${ }^{27}$ and growing evidence indicates that the loss of biodiversity can have a significant 
environmental impact. Natural resources are, by definition, finite; water, land, and fossil fuels will not be available for future generations if not well managed.

\section{Methodologies used to quantify the environmental impact of consumption and production}

Concerning quantification of food consumption patterns' impact on the environment, a significant amount of work has been anticipated, and therefore, various tools and analytical methodologies have been suggested. GHGE and utilization of natural resources for agriculture constitute the environmental impacts that were most frequently modelled. Several authors have examined the impact of habitual eating patterns on the environment among different population categories. Comparisons between dietary intakes, dietary recommendations, and theoretical diets were performed using numerous indicators such as greenhouse gas (GHG), land use (LU) and agricultural capacity, water use, throughout the Life Cycle Analysis (LCA). This effective tool uses mass as the functional unit (FU) ${ }^{28}$, standardized by the International Organization for Standardization ${ }^{29}$. GHGE is generally expressed in $\mathrm{kgCO}_{2}$ eq per $\mathrm{kg}$ of food item. Nevertheless, this GHGE expression be corrected otherwise to the daily or weekly of yearly amount of food item consumed per capita.

An Italian research team used the environmental hourglass approach, based on a LCA, to examine whether acquiescence with nutritional recommendations could reduce some negative environmental effects on the food production ${ }^{30}$.

Because of some limitations of LCA, another Italian group of researchers ${ }^{31}$ used a method they called hybrid input-output analysis (IOA)-LCA. The IOA-LCA approach consists of taking into consideration the positive aspects of the LCA and the IOA. This hybrid approach consists of taking into consideration the positive aspects of the life cycle assessment and the 
input-output analysis. IOA could assign emissions to various sectors, considering the overall country's economy, and provides researchers the opportunity to get, on one hand, authentic estimates of the environmental impact of food consumption based on per-capita consumption and, on the other hand, to have complete and accessible data against the constraints of collecting a huge quantity of information.

In sum, the hybrid method is primarily based on products' life cycle from specific categories of products. Through this method, some stages of the cycle could be accounted either through standard LCA or via IOA ${ }^{31}$. The same authors do not consider that GHGE and energy consumption are representatives of all the environmental impacts related to food production and consumption.

\section{The Mediterranean diet impact on greenhouse gas emissions and Land use}

In 2010, the United Nations Educational Scientific and Cultural Organisation (UNESCO) recognized the MDiet as an intangible heritage of humanity. The MDiet is a traditional diet distinguished by potential utilization of olive oil with a considerable consumption of plant and plant-based foods such as vegetables, fruits, cereals, legumes, seeds and nuts; moderate consumption of seafood, fermented dairy products, eggs and poultry; and lower intake of red and processed meats (RPM) and sweets ${ }^{32}$. This dietary pattern is healthy and nutritious, including foods with various components promoting health.

In addition to its environmental positive impact, the MDiet pattern is associated with reduced prevalence of type 2 diabetes and some types of cancers and neurodegenerative pathologies ${ }^{33}$. Reduced total mortality, reduced risk of developing metabolic syndrome with its components, and cardiovascular diseases reflect the protective effects of this diet pattern ${ }^{34-37}$. 
The low environmental impact of the MDiet is based on sustainable farming systems ${ }^{38}$, primarily as it constitutes a more plant-based diet and thus is envisaged as an eco-friendly diet.

During the last decades, several studies have assessed the environmental sustainability of MDiet. When compared to current Western dietary patterns, the MDiet can be considered a plant-based diet with lower GHGE and lower water footprints ${ }^{39}$. However, other authors have recently stated that plant-based diets from greenhouses may not have the lower environmental impact these plant-based diets are qualified with and tend to increase GHGE when consumption of such dietary patterns increases ${ }^{40-42}$.

Van Dooren and Aiking ${ }^{43}$ calculated a score (cf. formula 01), they called health score, based on 10 nutritional characteristics of three diets in the Netherlands; MDiet, New Nordic Diet (NND) composed of local Scandinavian traditional products, and Low Lands Diets (LLD) with and-identical health benefits as the NND. The LLD is a semi-vegetarian dietary pattern is characterized by a traditional, mostly plant-based diet, with high consumption of fresh and local vegetables, fruits and whole grains. Furthermore, the LLD provides a local vegetable oil such as rapeseed oil with limited quantities of fish, meat, milk, and eggs.

Another score was calculated by the same authors called Combined GHGE-LU Score. This score is presented as the average of the GHG and LU score per diet based on LCA. The MDiet scored 122 with the health score formula, which exceeds the recommendations. However, males scored 90 with Combined GHGE-LU Score and remain below the formulated goals $(=100)$. The score was defined as the average of the GHG and LU score per diet as shown by Van Dooren, et al. ${ }^{44}$.

In their studies, Tilman ${ }^{6}$ and Clark ${ }^{7}$ compiled data to make comparison between reference diets (considering all food groups) to three dietary patterns alternatives: MDiet; being 
abundant in vegetables and fruit, seafood and other foods); pescatarian diet (PD); which includes fish and virtually no meat (both red and poultry); and a vegetarian diet (VD), composed of dairy products and eggs as well as vegetables and fruits and grains with virtually no meat or fish. An important reduction $(\mathrm{P}<0.05)$ in adverse health indicators such as type 2 diabetes $(16-41 \%)$ and cancer $(7-13 \%)$ incidence was recorded across the three alternative diets. Moreover, heart disease mortality (20-26\%) and overall mortality (0-18\%) also decreased across the three alternative diets. Concerning environmental impact, these authors assessed GHGE and LU in 120 published papers which contain 555 lifecycle assessment (LCA) considering 82 food types. They concluded that GHGE are highest when animal products are consumed especially ruminant meat. GHGE are reduced for diets containing larger amounts of most cereals, fruits, vegetables and pulses (beans, lentils, and peas).

For an average Italian family, when the MDiet pattern is applied, the monthly expenditure is $€ 441.77$ being nearly identical to the national average food consumption budget $(€ 440.12)$ with a different proportion of each product class ${ }^{31}$. In the same study, authors found that the MDiet requires $\underline{3817.41} \mathrm{MJ}$ per month in energy consumption, lower than the actual MJ for the national average and lower than the healthy diet ( $2.44 \%$ and $4.36 \%$ respectively). However, the vegetarian diet pattern represented the lowest energy consumption $(\underline{3790.13}$ $\mathrm{MJ} / \mathrm{month}$ ), $0.71 \%$ less than the MDiet and 3.24\% less than the Italian average.

Concerning GHGE, the Italian national average diet pattern presented the highest monthly GHGE with $\underline{402.91} \mathrm{~kg} \mathrm{CO}_{2 \mathrm{eq}}$. The Health diet contributes the second largest amount of GHG emissions, at $2.28 \%$ less than the Italian diet, followed by the MDiet, which is $6.81 \%$ lower. The vegetarian diet showed the lowest emission rate of $14.55 \%$ below the national average and $6.74 \%$ below the MDiet ${ }^{31}$. 
The vegetarian diet pattern appears more environmentally sustainable than the MDiet.

However, for social, cultural and psychological or even ecological considerations, willingness to $\underline{\text { replace/reduce meat with vegetables and/or plant-based proteins might be a difficult goal to }}$ achieve $^{45}$. The MDiet could represent a practical alternative bridging the need to decrease the impact of food consumption on the environment and maintaining the social/cultural aspect of dietary behaviour. For maintaining the heritage of the MDiet, this balance should be considered when developing policies to reduce GHGE.

A recent systematic review ${ }^{46}$, included 18 studies on $\mathrm{GHG}$, four studies on energy use and three studies on water use. Comparisons have been made between both health and environmental outcomes with different methodologies including modelling (food components), LCA, and LU analysis. The environmental impacts modelled were GHGE and natural resources utilization, such as lands used for agriculture, energy consumption and water. Analysis of those studies revealed that reduced meat consumption improves health outcomes, and reduces GHGE as well as land, energy, and water usage.

Concerning GHGE based on a per gram of protein basis, the major difference of about 250-fold was recorded between ruminant meats mainly for beef and lamb, and legumes. Semivegetarian and vegetarian diets should reduce GHGE and mortality rates when compared with nonvegetarian diet ${ }^{46}$. The lowest health score and the highest environmental impact was observed in Italian average diet, where beef meat represented the food with the most significant projected impact on natural resources and on the ecosystem ${ }^{8}$. Conversely, the vegan diet showed the lowest environmental impact and the highest health score. In the United States, land, water usage and energy were higher in the American meat-based diet -compared to lacto-ovo 
vegetarian diet ${ }^{46}$. However, using other indicators of nutritional quality, a French study showed that among four dietary patterns, not every diet showing highest nutritional quality, as substituting fruit and vegetables for meat, could reduce GHGE ${ }^{47}$. Except for ruminant meat group, as shown in EPIC-Oxford cohort in the United Kingdom, among self-selected meat and fish eaters, vegetarians, and vegans ${ }^{48}$ and in the Netherlands Dutch diet ${ }^{44}$, the same authors draw a conclusion that the high-quality diet with high vegetable and fruit consumption had elevated GHG emissions compared to the low-quality diet characterized by starches, sweets, and salted snacks consumption. In a UK study, the highest GHGE amounts were observed among people consuming $>100 \mathrm{~g} / \mathrm{d}$ of meat. The emissions diminished when meat intake decreased from $50-99 \mathrm{~g} / \mathrm{d}$ to $<50 \mathrm{~g} / \mathrm{d}$. The emissions become the lowest in fish consumers, vegetarian individuals, and vegans ${ }^{48}$. The GHGE, LU, water and energy usage decreased in Spanish MDiet pattern ${ }^{49}$.

In the previously cited systematic review ${ }^{46}$, a UK study observed that lowest RPM plus vegetarian decreased GHGE by $0.47 \mathrm{~kg} \mathrm{CO}_{2}$ eq.person ${ }^{-1} \cdot \mathrm{d}^{-1}(12 \%)$ to $3.96 \mathrm{~kg} \mathrm{CO}_{2}$ eq person ${ }^{-1} \cdot \mathrm{d}^{-1}$ in men and $3.02 \mathrm{~kg} \mathrm{CO}_{2}$ eq. person ${ }^{-1}$. $\mathrm{d}^{-1}$ in women vs. current diet with a yearly GHGE decrease of 27.8 million tons. According to the UK government, variations in livestock production will not be sufficient to achieve emission reduction targets.

In Italy, Baroni, et al. ${ }^{8}$ made a comparison between seven diet patterns: omnivorous, organic farming; omnivorous, conventional farming; vegan, organic farming; vegan, conventional farming; vegetarian, organic farming; vegetarian, conventional farming and average Italian diet with conventional farming. They concluded that beef was the primary food displaying the highest environmental impact. Milk, cheese, and could also contribute to a high impact. 
In a French cross-sectional study (INCA-2), Masset, et al. ${ }^{50}$ compared four diet patterns according to their GHGE and cost between men and women. Authors showed that the major food components contributing to the increase in the daily GHG in the average French diet were meats. Another French study carried out by Drewnowski, et al. ${ }^{51}$ reported identical observations for 661 different foods and beverages. Meat, meat products, and dairy products expressed the highest amounts of GHGE per $100 \mathrm{~g}$ product compared to frozen and processed fruits, vegetables, grains and sweets.

Saez-Almendros, et al. ${ }^{52}$, analysed through LCA, the impact of production through transportation and retail on four dietary patterns, including the new MDiet pyramid in Spain. The authors showed that the MDiet, when compared to the other diet patterns, would diminish GHGE that reach $35,510 \mathrm{Gg} \mathrm{CO}_{2 \text {-eq }}$ year-1 $(72 \%)$, land use at $58 \%$, energy at $52 \%$, and water at $33 \%$. The annual GHGE of $\mathrm{CO}_{2} 35,510 \mathrm{Gg} \mathrm{CO}_{2 \text {-eq }}$ year ${ }^{-1}$, water consumption $13.2 \mathrm{Km}^{3}$ year-1, and agricultural LU 8,365 $\left(10^{3} \mathrm{Ha} \mathrm{year}^{-1}\right)$ were the lowest too in the MedDiet pattern. The authors concluded that switching from the current Spanish pattern to the MDiet using the new MDiet pyramid would be advantageous for consumers' health as well as the environment.

In a global modelling and data analysis performed by Tilman and Clark ${ }^{6}$ on the four previously mentioned diets, the MDiet pattern displayed a reduction of $30 \%$ in GHGE $(\sim 0.8 \mathrm{Gt}$ $\mathrm{CO}_{2}-\mathrm{C}_{\mathrm{eq}}$ per year), where ruminant meats showed the highest impact $\left(\mathrm{CO}_{2}-\mathrm{C}_{\mathrm{eq}}: \underline{0.023 \pm 0.002}\right.$ $\mathrm{g} / \mathrm{MJ} / 330 \pm 18 \mathrm{~g} /$ serving and $62 \pm 3.4 \mathrm{~g} / \mathrm{g}$-protein). Omnivorous diets are expected to require more crop land (370-740 million Ha) than MDiet, vegetarian and pescatarian diets.

Comparatively, in the Netherlands modelling and data analysis performed by Van Dooren and Aiking ${ }^{43}$, the MDiet pattern exhibited, compared to the other diet patterns, the highest health score (118), an acceptable GHG index $96\left(3.4 \mathrm{Kg} \mathrm{CO}_{2 \mathrm{eq}} / \mathrm{d}\right)$, the lowest $\mathrm{LU}$ index $107\left(2.75 \mathrm{~m}^{2}\right.$ 
year $^{-1}$ day $^{-1}$ ) and was second only to the vegan diet (130) in Sustainability with a score of score of 102 .

In an previous study, comparing six dietary patterns: current average Dutch, official "recommended" Dutch, vegetarian, semi-vegetarian, vegan diet and MDiet, Van Dooren, et al. ${ }^{44}$ found that the MDiet (96) and semi-vegetarian diet (96) both were close to reference score (100). Furthermore, the same authors reported that the four diets had a GHGE score closer to the European Union's target (20\%) of GHG reduction. The vegan diet exceeded the reference score (123). The greatest reduction in GHGE and LU could be achieved with limited consumption of meat, dairy products, calorie-dense foods, and beverages such as alcoholic, juices, soft drinks, coffee, and tea, in the given order. The reduction of meat consumption is the most effective option since this group was implicated in increasing GHGE emissions to $34 \%$ (considering the use of household energy) and $54 \%$ of LU. The authors of this study stated that even consuming a considerable amount of vegetables and fruits, pulses, and some more (whole grain) cereals and shifting to olive oil, will only slightly impact the climate.

Recently, an investigation was conducted by Naja, et al. ${ }^{53}$ from previous national survey data on 337 adults using a 61-item FFQ. Three dietary patters were assessed: LebaneseMediterranean, Western, and High-Protein. Environmental footprints of the three food consumption patterns were compared. The Lebanese-MDiet showed lower water consumption $(\underline{602.06-1 \pm 330.70} \mathrm{~L} / \mathrm{d})$ and $\mathrm{GHG}$ emissions $\left(0.90 \pm 0.56 \mathrm{Kg} \mathrm{CO}_{2 \mathrm{eq}} / \mathrm{d}\right)$. However, the other patterns displayed high environmental footprints: Western $\underline{1231.0 z \pm 937.23} \mathrm{~L} / \mathrm{d} / 1.58 \pm 1.23$ $\mathrm{CO}_{2 \mathrm{eq}} / \mathrm{d}$, High-Protein: $653.879 \pm 452.9 z \mathrm{~L} / \mathrm{D} / 1.40 \pm 0.99 \mathrm{CO}_{2 \mathrm{eq}} / \mathrm{d}$, respectively. Moreover, for the Lebanese-MDiet, whole dairy products significantly contributed to increased water use to $43.01 \%$ when vegetables substantially increased energy use to $60.12 \%$ and GHGE to $50.75 \%$. 
Concerning the High-Protein diet, the most elevated contributor to all three environmental footprints were meat products which increased water consumption to $69.30 \%$, energy use to $50.87 \%$ and GHGE to $73.08 \%$.

According to Rosi, et al. ${ }^{54}$, few studies based on real food intakes have been carried out, and their three key environmental indicators were water footprint, carbon footprint, and ecological footprint. The originality of this study includes assessment of environmental impact of three diets among 153 Italian adult consumers, equally distributed to omnivores, ovo-lactovegetarians, and vegans. The Italian Mediterranean index was calculated to assess the nutritional quality of the three diets and both, with food group intakes, were presented as medians and interquartile range. The three dietary groups displayed different levels of adherence to the MDiet. The MD index was significantly $(\mathrm{p}<0.05)$ higher in the vegan category, 7.0 , and significantly $(\mathrm{p}<0.05)$ lower for the omnivore category, 4.0. The environmental impacts' analysis of the three diet categories indicated that omnivores' diet was the most significant diet affecting the three environmental indicators. This pattern produced significantly higher carbon, water, and ecological footprints $(p<0.001)$ when compared to the other diets. It should be noted that meat and fish categories' contribution to the omnivorous diet was: $38 \%$ for the water footprint, $37 \%$ for the carbon footprint, and $44 \%$ for the ecological footprint. Cereals and derivatives, then further vegetable-based foods accounted for $24 \%, 56 \%$, and $84 \%$ of the carbon footprint; $31 \%$, $69 \%$, and $92 \%$ of the water footprint; and $21 \%, 58 \%$, and $90 \%$ of the ecological footprint for the omnivores, ovo-lacto-vegetarians, and vegan groups, respectively. The authors mentioned in their conclusion that Italians appear to have a moderately high adherence level to the MDiet. A recently published study called the Seguimiento Universidad de Navarra (SUN) project, by Fresán, et al. ${ }^{55}$, assessed an overall sustainable diet considering simultaneously 
health, environment and monetary cost on a sample of 18,429 Spanish university graduates. Trichopoulou, et al. ${ }^{56}$ measured the adherence to the MDiet through a suggested index. The SUN project authors designed an index they named Overall Sustainable Diet Index that considers the impact of the daily diet on environmental footprints, health, and monetary costs. A score-A score was assigned to each attribute. The dietary patterns of participants were clustered in the upper quartile. The MDiet was the most sustainable pattern followed closely by the Provegetarian dietary pattern. However, although considered the healthiest option and exhibiting relatively low environmental footprints, the MDiet financial cost was the highest. The Provegetarian dietary pattern represented the most eco-friendly pattern, positively affecting health and lowering cost.

In the same country (Spain), an LCA approach has been recently performed by BatlleBayer, et al. ${ }^{57}$ to assess the nutritional quality of the current food consumption and GHGE. Comparisons have also been made with two alternative diets; the first was called Strategy for Nutrition, Physical Activity and the Prevention of Obesity (NAOS) Strategy. NAOS, launched by the Spanish Ministry of Health and Consumer Affairs, refers to the dietary guidelines of Spain. The second diet was based on the MDiet. A common functional unit was applied to the three types of diets for comparison purpose; that consists of a food basket with the representative food products consumed yearly inside and outside home by a Spanish citizen including around $790 \mathrm{~kg}$ of food and drink products $(\underline{11.16 \mathrm{MJ} / \mathrm{d} 2665 \mathrm{kcal} / \mathrm{d}})$. This average daily calorie intake emits approximately $1.6 \mathrm{t} \mathrm{CO}_{2}$ eq per year (1.4 to $2.0 \mathrm{t} \mathrm{CO}_{2}$ eq). When adjusted to a food basket that covers the average recommended calorie intake, an amount of $1.4 \mathrm{t} \mathrm{CO}_{2}$ eq per year is emitted. Animal-based products significantly contributed to this effect as follow: meat (33\%), fish (22\%), dairy products (17\%), vegetables (5\%), and cereals with derivates $(5 \%)$ and 
beverages (5\%). Comparatively, the MDiet and the food baskets emit 1.2 to $1.3 \mathrm{t} \mathrm{CO}_{2}$ eq, respectively because of the reduced meat consumption. The leading contributors for both food baskets were the dairy products that represented $33 \%$ and $26 \%$ for NAOS and MEDiet, respectively. Fish represented $18 \%$ and $12 \%$; vegetables $12 \%$ and $22 \%$, while meat accounted for $12 \%$ and $13 \%$ for both diets in respective orders.

An Italian team ${ }^{58}$ explored, through a review paper, the natural resources-food nexus in the Mediterranean region and focused on the ecological footprints (EF) of existing consumption and production patterns. In addition, statistics obtained from various international databases, such as the FAOSTAT, and other sources, were utilized to examine the situation over 21 countries of Mediterranean region. It has been highlighted from this ecological analysis that $\mathrm{EF}$ of consumption of almost all of the 21 Mediterranean countries were constantly higher compared to production's EF. The carbon footprint (CF) itself was higher than the biocapacity, with the exception of seven countries.

Regarding water footprint (WF), consumption of meat products contributed one-third to the entire WF in Bosnia and Italy. Cereals' contribution to WF was the highest in Egypt, Morocco, and Turkey, where cereal accounted up to one-third of water use. For vegetable oils, such as olive oil, the contribution to the WP was solely significant in Italy. However, meat and dairy products, accounted for one- half of the total WF of Italian and Bosnian food supply.

American authors discussed, in their review ${ }^{9}$, how shifting to healthier diets, such as some Mediterranean, vegetarian, vegan and pescatarian diet patterns, could have a positive effect on diet-related disease incidence as well as ameliorate environmental outcomes. LCA metaanalyses shows that plant-based foods display the lowest GHGE per kilocalorie of food produced. Compared to the previous group, dairy products, eggs, pork, poultry, and low-impact 
fish production systems contribute approximately 100 to $2500 \%$ higher GHGE which are higher. Beef, sheep, and goat meats have GHGE ranging between $2,000 \%$ to $10,000 \%$ higher than plantbased foods per kilocalorie of food produced. Furthermore, meat production recorded the highest levels of nutrient pollution; $\sim 10,000 \%$ higher than plant-based foods.

It should be emphasized that diets which produce minor environmental effects are not necessarily healthy. Whereas, healthier diets do not necessarily have a lower environmental impact. So, substituting foods within a diet could positively impact health, but might decrease or increase GHGE.

\section{Land use}

Since 1961, land used for global agriculture has increased by $15 \%$. Compared to other dietary patterns, plant-based diets like the MDiet require less land per kilocalorie of food produced. For instance, ruminant meats need 20 to 100 times more land than plant-based foods ${ }^{9}$. Nelson, et al. ${ }^{46}$ found in their systematic review that adherence to a diet lower in animal-based foods and total energy and rich in plant-based foods, such as the MDiet, has lower environmental impacts and promotes greater health. Shifting toward MDiet appears to deal with both health and environmental concerns ${ }^{59}$.

Saez-Almendros, et al. ${ }^{52}$ compared the MDiet with the $w$ Western diet based on the American diet and the Spanish diet patterns from the FAO food balance sheets and from the Household Consumption Surveys of the Spanish Ministry of Agriculture, Food and Environment. The agricultural LU of the MDiet was $8365.10^{3} \mathrm{Ha} /$ year, the lowest among the other diets, a reduction of $58 \%$ when compared to the Western diet. Similarly, a higher 
adherence to the MDiet in Spain resulted in a reduction of LU (mean for the highest versus lowest adherence category to MDiet $\left.=-0.71(95 \% \mathrm{CI}-0.76,-0.66) \mathrm{m}^{2} / \mathrm{d}\right){ }^{55}$.

Furthermore, Van Dooren, et al. ${ }^{44}$ compared the LU of six diets for female adults in the Netherlands. The MDiet had a land use of $2.8 \mathrm{~m}^{2 *}$ year/day, lower than the average Dutch diet, the recommended Dutch dietary pattern and the semi-vegetarian diet, but higher than the vegetarian and the vegan diets. LU is mostly attributed to the amount of meat in the diet (54\%) along with processed foods (snacks, pastries, sweets, etc. 18\%) and dairy products (11\%). The LU estimate for the MDiet (4.15 $\mathrm{m}^{2 *}$ year) was similar to the present Dutch diet and higher than the NND and LLD patterns for adult men and it did not meet the Dutch dietary guidelines (3.08 $\mathrm{m}^{2 *}$ year) ${ }^{43}$.

\section{Water use}

Water footprint is a measure of the water resources required for the production of goods. Water footprint takes into account blue water that contains fresh surface water and/or groundwater, green water which is composed of soil and crop plants' rainwater evapotranspiration, and grey water made up of polluted water resulting from the production process ${ }^{60}$.

Compared with western dietWestern diets, the MDiet has a lower environmental impact ${ }^{61,62}$, particularly its reduced water use which constitutes an additional argument in favor of the MDiet, since water scarcity is a challenging and worrying issue all over the world ${ }^{63}$. In fact, better adherence of a Spanish population to the MDiet resulted in a reduction of $33 \%$ of water consumption ${ }^{52}$. In the same context, Fresan, et al. ${ }^{64}$ found that the mean for the highest vs. lowest adherence category to MDiet $=-58.88(95 \% \mathrm{CI}-90.12,-27.64)$ 1/day. 
Studies showed that adopting the MDiet could result in reducing the water footprint up to $29 \%$ in the United States, which is a decrease by 1629 1/person/day ${ }^{65}, 750$ 1/capita day in Spain ${ }^{65}$, and $30001 / \mathrm{kg}$ of food product per week in Italy ${ }^{18}$. A study in Lebanon found that MDiet had the lowest water consumption compared to the western dietwestern diet and the high-protein diet $243.35 \pm 112.0,443.61 \pm 197.15,264.72 \pm 161.671 / \mathrm{kg}$ per $4.18 \mathrm{MJ} 1000$ Keal-respectively ${ }^{53}$.

Growing evidence suggests that the dietary pattern which is rich in plant-based foods and poor in animal-based foods exerts less environmental impact including water use $(10,17,41)$. Moreover, two studies explored the environmental impact of three different diets. The omnivorous diet comprises food of animal (including animal flesh) and plant origin, the lactoovo-vegetarian diet which includes plant-based food and animal products (excluding animal flesh), and the vegan dietary pattern which is an exclusively plant-based menu. Both studies concluded that the lacto-ovo-vegetarian and the vegan diets which were more adherent to the MDiet had a lower impact on the water footprint compared with the omnivorous dietary pattern 54,66. Furthermore, Lacirignola, et al. ${ }^{58}$ showcased in a review article the importance of the promotion of the MDiet on preserving water resources and emphasis on reducing food waste in the production chain to make it even more sustainable. The food industry, and particularly the dairy, meat, and fruit and vegetable processing sectors, is one of the most water-consuming industries ${ }^{61}$.

\section{Energy consumption}

The current food system is considered ineffective, environmentally unsustainable, and highly dependent on low-price fossil fuels ${ }^{67}$. Furthermore, a Spanish study of university graduates compared the environmental footprints of several diets concluded that the MDiet and 


\section{Affordability}

Towards the end of the 1990s, a growing interest in financial costs of food products with regard to their consumption was perceived ${ }^{68}$. Since then, an upsurge in studies assessing health, environment and monetary costs, separately or focusing on these different metrics at the same time has been observed ${ }^{69,70}$. Seconda and colleagues performed a comparison between four groups of participants by evaluating the organic food part in their diet; (Organic vs. 
Conventional) and the MDiet adherence (Med vs. NoMed). The higher cost (euro/day) was observed on the Organic-MDiet (11.43 [95\% CI=11.34-11.52]) comparing to the Organic-Non MDiet, Conventional-MDiet and Conventional-Non MDiet (10.90 [95\% CI=10.81-10.98], 9.11 $[95 \% \mathrm{CI}=9.03-9.19]$ and $8.59[95 \% \mathrm{CI}=8.55-8.63]$, respectively) ${ }^{70}$.

Recommendations of the Spanish SUN project (Seguimiento Universidad de Navarra, University of Navarra Follow-up) showed that plant-based diets, especially the MDiet and a provegetarian diet model, might be a good option to accomplish a complete sustainable diet, according to a high score bringing together the three dimensions of a healthy, affordable and environmentally friendly diet ${ }^{55}$. These authors assessed three dietary patterns (the Mediterranean, the Western and the Pro-vegetarian dietary patterns) for monetary costs. Participants with higher adherence to the MDiet spent $€ 1.42 /$ day more in their daily diet comparing to those with adherence to the two other diets ${ }^{55}$.

In their study performed in the Northern Bank of the Mediterranean (Italy), suggested that the substitution of animal-based products with vegetable proteins might lead to a significant decrease in $\mathrm{CO}_{2 \mathrm{eq}}$ emission and resource reduction, at the same cost for consumers. This indicates that food choice based on environmental and health goals is not necessarily more costly. However, other Italian authors, who found that the monthly expenditure of the MDiet was somewhat higher in the total budget compared to the regular expenditure on food by the Italian population, reported remarkable results even with a clear difference in the budget distribution by different food groups ${ }^{18}$. By comparing the cost (in Euro) of the MDiet to the ordinary Italian household food consumption, the cost of the MDiet was higher at about 0.7 euro/week per person especially regarding milk, cheese and eggs ( 20 vs. 14.06 euros) and regarding potatoes, fruit and vegetables (34 vs. 16.36 euros) ${ }^{18}$. 
The idea that the reliance on the MDiet is relatively expensive was also the most important conclusion from a French study showing that consumers following the MDiet pattern with a higher intake of organic food fit the previous definition of sustainability published by the FAO, except for economic considerations ${ }^{72}$.

In a very recent multidisciplinary literature review, combining evidence from several fields (nutritional sciences, health, environmental, agricultural and sustainability studies) on the diets impacts on the environment, ecosystems, and the rural landscape, a Portuguese team has drawn conclusions of the need to promote and invest in the financial viability of the MDiet as a "modern" affordable diet for consumers in general and as a mean to reduce chronic diseases ${ }^{38}$.

\section{Sustainability}

According to the definition provided by Conway ${ }^{73}$; "Sustainability is the ability of a system to maintain productivity in spite of a major disturbance, such as caused by intensive stress or a large perturbation" 73 . The main sustainable advantages of the MDiet are currently characterized by health ${ }^{74}$ and nutrition benefits, with positive effects on biodiversity richness and environmental impact. In addition, the MDiet is also characterized by a low consumption of animal products, conservation of water resources and a reduction of GHGE with high sociocultural food values and positive local economic returns 16,75,76. At the end of 2010, the UNESCO added the MDiet in the Representative List of the Intangible Cultural Heritage of Humanity, and described it as follows: "The MDiet-derived from the Greek word diaita, way of life- is the set of skills, knowledge, rituals, symbols, and traditions, ranging from the landscape to the table, which in the Mediterranean basin concerns the crops, harvesting, picking, fishing, animal husbandry, conservation, processing, cooking, and particularly sharing and consuming 
of food" ${ }^{77}$. In parallel with this recognition of UNESCO, Serra-Majem, et al. ${ }^{76}$ collected key documents presented at the $8^{\text {th }}$ International Conference on the MDiet, held in Barcelona in 2010, which focused on issues related to food sustainability and how food production and transport contribute to the impacts of climate change. The most significant recommendations were to update trends and developments around the MDiet, helping to improve access, raise awareness among health and nutrition professionals and, ultimately, encourage compliance and the population in a sustainable and coherent manner ${ }^{76}$.

In the field of nutrition, an Italian team of researchers has developed a methodological approach and a nutritional sustainability index for agri-food products ${ }^{78}$. Their approach is founded on two macro-indicators; the first one, named "business distinctiveness", which considers the different standards and regulations relating to quality, safety and traceability, as well as the origin of raw materials; while the second macro-indicator, known as "nutritional quality", assesses the micronutrients and bioactive phytochemicals quality composition of the product. Based on typical products and Mediterranean food groups, the proposed index could be a highly valuable guide to assess both the sustainability and the diet overall quality ${ }^{78}$. However, concerns remain about the sustainability of family eating practices in the Mediterranean region. Policy makers and marketers need to take initiatives that focus on education and facilitate access to sustainable food products that are specific to the MDiet in the Mediterranean. ${ }^{79,80}$.

According to a recent study on the guiding principles for sustainable development, three suggestions to increase the sustainability of the MDiet could be applied to the Mediterranean region; more plant foods, reducing food waste, and consuming less meat ${ }^{81}$. Furthermore, in 2016, on behalf of the Scientific Committee of the International Foundation of MDiet, Dernini et al. ${ }^{82}$ proposed the "Med Diet 4.0: the MDiet with four sustainable benefits" based on potential 
indicators that can help to assess the sustainability of the MDiet. These indicators are; (A) Nutrition and Health, (B) Environment, (C) Economy, and (D) Society and culture. The Med Diet 4.0 can play a vital, educational and communicative role in revitalizing the MDiet by providing a larger understanding of its sustainability features with country-specific and culturally appropriate applications. A conceptual framework (see figure 2) is proposed to illustrate the dynamic interactions and interrelations between environmental health promotion and the MDiet.

\section{Conclusion}

This thematic review explored the environmental health benefits of the MDiet Pattern (see Table 1). Global health efforts that combine environmental health policies with aspects of public health nutrition are warranted in light of the findings in this review. The MDiet, considered a plant-oriented dietary approach, appears to be an appropriate choice to preserve both human and environmental health and to reduce the environmental impact associated with food consumption. Regrettably, its erosion is a consequence of the loss of its adherence by the Mediterranean populations, which impacts health, social, cultural, economic and environmental trends. Preference should be attributed to diets characterised by low environmental impacts and providing sufficient quantities of macronutrients and micronutrients. The largest challenge presented based on this review is how to make the MDiet the dominant dietary lifestyle pattern for the majority of the people living in this region and whether this pattern might be globalized. Further challenges include how to effect consumer's behaviour change and make consumption more realistic. Diet cost, culture and social factors should also be considered in promoting MDiet as a sustainable and maintainable dietary pattern. 


\section{References}

1. Vermeulen SJ, Campbell BM, Ingram JS. Climate change and food systems. Annu Rev Environ Resour. 2012;37. doi: 10.1146/annurev-environ-020411-130608

2. Whitmee S, Haines A, Beyrer C, et al. Safeguarding human health in the Anthropocene epoch: report of The Rockefeller Foundation-Lancet Commission on planetary health. Lancet. 2015;386(10007):1973-2028. doi:

3. Carpenter SR. Eutrophication of aquatic ecosystems: bistability and soil phosphorus. Proc Natl Acad Sci. 2005;102(29):10002-10005. doi: 10.1073/pnas.0503959102

4. Bajželj B, Richards KS, Allwood JM, et al. Importance of food-demand management for climate mitigation. Nat Clim Change. 2014;4(10):924. doi: 10.1038/nclimate2353

5. Houghton R. Carbon emissions and the drivers of deforestation and forest degradation in the tropics. Curr Opin Environ Sustain. 2012;4(6):597-603. doi: 10.1016/j.cosust.2012.06.006

6. Tilman D, Clark M. Global diets link environmental sustainability and human health. Nature. 2014;515(7528):518-522. doi: 10.1038/nature13959

7. Clark MA, Springmann M, Hill J, Tilman D. Multiple health and environmental impacts of foods. Proc Natl Acad Sci. 2019;116(46):23357. doi: 10.1073/pnas.1906908116

8. Baroni L, Cenci L, Tettamanti M, Berati M. Evaluating the environmental impact of various dietary patterns combined with different food production systems. Eur J Clin Nutr. 2007;61(2):279-286. doi: 10.1038/sj.ejcn.1602522

9. Clark M, Hill J, Tilman D. The Diet, Health, and Environment Trilemma. Annu Rev Environ Resour. 2018;43(1):109-134. doi: 10.1146/annurev-environ-102017-025957

10. Scarborough P, Allender S, Clarke D, Wickramasinghe K, Rayner M. Modelling the health impact of environmentally sustainable dietary scenarios in the UK. European journal of clinical nutrition. 2012;66(6):710. doi:

11. Behrens P, Kiefte-de Jong JC, Bosker T, Rodrigues JF, De Koning A, Tukker A. Evaluating the environmental impacts of dietary recommendations. Proc Natl Acad Sci. 2017;114(51):13412-13417. doi: 10.1073/pnas.1711889114

12. Alexandratos N, Bruinsma J. World agriculture: towards 2030/2050 - The 2012 revision. Rome, FAO: Food and Agriculture Organization of the United Nations.;2012.

13. United Nations Department of Economic and Social Affairs Division for Sustainable Development Goals. Sustainable Development Goals. 2020; https://sustainabledevelopment.un.org/?menu=1300 Accessed January 2, 2020.

14. Nordin SM, Boyle M, Kemmer TM. Position of the Academy of Nutrition and Dietetics: Nutrition Security in Developing Nations: Sustainable Food, Water, and Health. J Acad Nutr Diet. 2013;113(4):581-595. doi: 10.1016/j.jand.2013.01.025

15. Development USAfI. Strengthening Partnerships, Results, and Innovations in Nutrition Globally project - Systems Thinking and Action for Nutrition. 2015; https://www.springnutrition.org/publications/briefs/systems-thinking-and-action-nutrition. Accessed January $17,2020$.

16. Food and Agriculture Organization of the United Nations. Sustainable diets and biodiversity - Directions and solutions for policy, research and action. 2010; http://www.fao.org/3/a-i3004e.pdf. Accessed September 24, 2019.

17. Giraldi G, De ELdA. Dietary habits in Italy: the importance of the Mediterranean diet. Ann Ig. 2012;24(4):311-317. doi: 
18. Germani A, Vitiello V, Giusti AM, Pinto A, Donini LM, del Balzo V. Environmental and economic sustainability of the Mediterranean Diet. Int J Food Sci Nutr. 2014;65(8):10081012. doi: 10.3109/09637486.2014.945152

19. Springmann M, Godfray HCJ, Rayner M, Scarborough P. Analysis and valuation of the health and climate change cobenefits of dietary change. Proc Natl Acad Sci. 2016;113(15):4146-4151. doi:

20. Statovci D, Aguilera M, MacSharry J, Melgar S. The impact of western diet and nutrients on the microbiota and immune response at mucosal interfaces. Front Immunol. 2017;8:838. doi:

21. Alexander P, Rabin S, Anthoni P, et al. Adaptation of global land use and management intensity to changes in climate and atmospheric carbon dioxide. Glob Change Biol. 2018;24(7):2791-2809. doi:

22. Vega Mejía N, Ponce Reyes R, Martinez Y, Carrasco O, Cerritos R. Implications of the Western Diet for Agricultural Production, Health and Climate Change. Front Sustain Food Syst. 2018;2(88). doi: 10.3389/fsufs.2018.00088

23. Popkin BM, Adair LS, Ng SW. Global nutrition transition and the pandemic of obesity in developing countries. Nutr Rev. 2012;70(1):3-21. doi:

24. Springmann M, Wiebe K, Mason-D'Croz D, Sulser TB, Rayner M, Scarborough P. Health and nutritional aspects of sustainable diet strategies and their association with environmental impacts: a global modelling analysis with country-level detail. Lancet Planet Health. 2018;2(10):e451-e461. doi: 10.1016/S2542-5196(18)30206-7

25. Food and Agriculture Organization of the United Nations. Rome declaration on world food security and world food summit plan of action. 1996; http://www.fao.org/docrep/003/w3613e/w3613e00.htm. Accessed December 11, 2019.

26. Food and Agriculture Organization of the United Nations. The future of food and agriculture: Trends and challenges. 2017; http://www.fao.org/3/a-i6583e.pdf. Accessed May 1, 2020.

27. United Nations Environment Programme. UNEP Year Book - Emerging issues in our global environment 2012. 2012; http://wedocs.unep.org/bitstream/handle/20.500.11822/8019/UNEP\%20Year\%20Book\%202012 Emerging\%20Issues\%20in\%20our\%20Global\%20E nvironment-20121085.pdf? sequence=5\&isAllowed=y. Accessed December 10, 2019.

28. Heller MC, Keoleian GA, Willett WC. Toward a Life Cycle-Based, Diet-level Framework for Food Environmental Impact and Nutritional Quality Assessment: A Critical Review. Environ Sci Technol. 2013;47(22):12632-12647. doi: $10.1021 /$ es4025113

29. International Organization for Standardization. ISO 14040:2006(en) - Environmental management - Life cycle assessment - Principles and framework. 2006; https://www.iso.org/obp/ui/\#iso:std:iso:14040:ed-2:v1:en. Accessed December 10, 2019.

30. Ulaszewska MM, Luzzani G, Pignatelli S, Capri E. Assessment of diet-related GHG emissions using the environmental hourglass approach for the Mediterranean and new Nordic diets. Sci Total Environ. 2017;574:829-836. doi: 10.1016/j.scitotenv.2016.09.039

31. Pairotti MB, Cerutti AK, Martini F, Vesce E, Padovan D, Beltramo R. Energy consumption and GHG emission of the Mediterranean diet: a systemic assessment using a hybrid LCA-IO method. J Clean Prod. 2015;103:507-516. doi: 10.1016/j.jclepro.2013.12.082 
32. United States Department of Health \& Human Services - Office of Disease Prevention and Health Promotion. Scientific Report of the 2015 Dietary Guidelines Advisory Committee. 2015; https://health.gov/dietaryguidelines/2015-scientific-report/. Accessed December 1, 2019.

33. Bach-Faig A, Berry EM, Lairon D, et al. Mediterranean diet pyramid today. Science and cultural updates. Public Health Nutr. 2011;14(12a):2274-2284. doi: $10.1017 / \mathrm{s} 1368980011002515$

34. Sofi F, Macchi C, Abbate R, Gensini GF, Casini A. Mediterranean diet and health status: an updated meta-analysis and a proposal for a literature-based adherence score. Public Health Nutr. 2014;17(12):2769-2782. doi: 10.1017/s1368980013003169

35. Kastorini CM, Milionis HJ, Esposito K, Giugliano D, Goudevenos JA, Panagiotakos DB. The effect of Mediterranean diet on metabolic syndrome and its components: a metaanalysis of 50 studies and 534,906 individuals. J Am Coll Cardiol. 2011;57(11):12991313. doi: 10.1016/j.jacc.2010.09.073

36. Schwingshack1 L, Hoffmann G. Adherence to Mediterranean diet and risk of cancer: a systematic review and meta-analysis of observational studies. Int $J$ Cancer. 2014;135(8):1884-1897. doi: 10.1002/ijc.28824

37. Rosato V, Temple NJ, La Vecchia C, Castellan G, Tavani A, Guercio V. Mediterranean diet and cardiovascular disease: a systematic review and meta-analysis of observational studies. Eur J Nutr. 2019;58(1):173-191. doi: 10.1007/s00394-017-1582-0

38. Campos S, Madureira L. Can Healthier Food Demand be Linked to Farming Systems' Sustainability? The Case of the Mediterranean Diet. Int J Food System Dynamics. 2019;10(3):262-277. doi: 10.18461/ijfsd.v10i2.17

39. Scoullos M, Ferragina E. Environmental and Sustainable Development in the Mediterranean. 2010; http://www.iemed.org/publicacions/10papers8.pdf. Accessed November 23, 2019.

40. Van de Kamp EM, Temme HME. Plant-Based Lunch at Work: Effects on Nutrient Intake, Environmental Impact and Tastiness-A Case Study. Sustainability. 2018;10(1). doi: $10.3390 /$ su10010227

41. Lacour C, Seconda L, Alles B, et al. Environmental Impacts of Plant-Based Diets: How Does Organic Food Consumption Contribute to Environmental Sustainability? Front Nutr. 2018;5:8. doi: 10.3389/fnut.2018.00008

42. Vieux F, Darmon N, Touazi D, Soler LG. Greenhouse gas emissions of self-selected individual diets in France: Changing the diet structure or consuming less? Ecol Econ. 2012;75:91-101. doi: 10.1016/j.ecolecon.2012.01.003

43. Van Dooren C, Aiking H. Defining a nutritionally healthy, environmentally friendly, and culturally acceptable Low Lands Diet. Int J Life Cycle Ass. 2016;21(5):688-700. doi: 10.1007/s11367-015-1007-3

44. Van Dooren C, Marinussen M, Blonk H, Aiking H, Vellinga P. Exploring dietary guidelines based on ecological and nutritional values: A comparison of six dietary patterns. Food Policy. 2014;44:36-46. doi: 10.1016/j.foodpol.2013.11.002

45. Sanchez-Sabate R, Sabaté J. Consumer Attitudes Towards Environmental Concerns of Meat Consumption: A Systematic Review. Int J Environ Res Public Health. 2019;16(7). doi: 10.3390/ijerph16071220 
46. Nelson ME, Hamm MW, Hu FB, Abrams SA, Griffin TS. Alignment of Healthy Dietary Patterns and Environmental Sustainability: A Systematic Review. Adv Nutr. 2016;7(6):1005-1025. doi: 10.3945/an.116.012567

47. Vieux F, Soler LG, Touazi D, Darmon N. High nutritional quality is not associated with low greenhouse gas emissions in self-selected diets of French adults. Am J Clin Nutr. 2013;97(3):569-583. doi: 10.3945/ajcn.112.035105

48. Scarborough P, Appleby PN, Mizdrak A, et al. Dietary greenhouse gas emissions of meat-eaters, fish-eaters, vegetarians and vegans in the UK. Clim Change. 2014;125(2):179-192. doi: 10.1007/s10584-014-1169-1

49. Martinez-Gonzalez MA, Bes-Rastrollo M. Dietary patterns, Mediterranean diet, and cardiovascular disease. Curr Opin Lipidol. 2014;25(1):20-26. doi: 10.1097/mol.0000000000000044

50. Masset G, Vieux F, Verger EO, Soler LG, Touazi D, Darmon N. Reducing energy intake and energy density for a sustainable diet: a study based on self-selected diets in French adults. Am J Clin Nutr. 2014;99(6):1460-1469. doi: 10.3945/ajcn.113.077958

51. Drewnowski A, Rehm CD, Martin A, Verger EO, Voinnesson M, Imbert P. Energy and nutrient density of foods in relation to their carbon footprint. Am J Clin Nutr. 2015;101(1):184-191. doi: 10.3945/ajcn.114.092486

52. Saez-Almendros S, Obrador B, Bach-Faig A, Serra-Majem L. Environmental footprints of Mediterranean versus Western dietary patterns: beyond the health benefits of the Mediterranean diet. Environ Health. 2013;12:118. doi: 10.1186/1476-069x-12-118

53. Naja F, Jomaa L, Itani L, et al. Environmental footprints of food consumption and dietary patterns among Lebanese adults: a cross-sectional study. Nutr J. 2018;17(1):85. doi: 10.1186/s12937-018-0393-3

54. Rosi A, Mena P, Pellegrini N, et al. Environmental impact of omnivorous, ovo-lactovegetarian, and vegan diet. Sci Rep. 2017;7(1):6105. doi: 10.1038/s41598-017-06466-8

55. Fresán U, Martínez-González MA, Sabaté J, Bes-Rastrollo M. Global sustainability (health, environment and monetary costs) of three dietary patterns: results from a Spanish cohort (the SUN project). BMJ Open. 2019;9(2):e021541. doi: 10.1136/bmjopen-2018021541

56. Trichopoulou A, Costacou T, Bamia C, Trichopoulos D. Adherence to a Mediterranean diet and survival in a Greek population. N Engl J Med. 2003;348(26):2599-2608. doi: 10.1056/NEJMoa025039

57. Batlle-Bayer L, Bala A, García-Herrero I, et al. The Spanish Dietary Guidelines: A potential tool to reduce greenhouse gas emissions of current dietary patterns. J Clean Prod. 2019;213:588-598. doi: 10.1016/j.jclepro.2018.12.215

58. Lacirignola C, Capone R, Debs P, El Bilali H, Bottalico F. Natural resources - food nexus: food-related environmental footprints in the mediterranean countries. Front Nutr. 2014;1:23-23. doi: 10.3389/fnut.2014.00023

59. Duchin F. Sustainable Consumption of Food: A Framework for Analyzing Scenarios about Changes in Diets. J Ind Ecol. 2005;9(1-2):99-114. doi: 10.1162/1088198054084707

60. Aldaya M, Chapagain A, Hoekstra A, Mekonnen M. The Water Footprint Assessment Manual - Setting the Global Standard. London: Routledge 2011. 
61. Alsaffar AA. Sustainable diets: The interaction between food industry, nutrition, health and the environment. Food Sci Technol Int. 2016;22(2):102-111. doi: $10.1177 / 1082013215572029$

62. Aboussaleh Y, Capone R, Bilali HE. Mediterranean food consumption patterns: low environmental impacts and significant health-nutrition benefits. Proc Nutr Soc. 2017;76(4):543-548. doi: 10.1017/s0029665117001033

63. Donini LM, Serra-Majem L, Bullo M, Gil A, Salas-Salvado J. The Mediterranean diet: culture, health and science. Br J Nutr. 2015;113 Suppl 2:S1-3. doi: $10.1017 / \mathrm{s} 0007114515001087$

64. Fresan U, Martinez-Gonzalez MA, Sabate J, Bes-Rastrollo M. The Mediterranean diet, an environmentally friendly option: evidence from the Seguimiento Universidad de Navarra (SUN) cohort. Public Health Nutr. 2018;21(8):1573-1582. doi: 10.1017/s1368980017003986

65. Blas A, Garrido A, Willaarts AB. Evaluating the Water Footprint of the Mediterranean and American Diets. Water. 2016;8(10). doi: 10.3390/w8100448

66. Ruini LF, Ciati R, Pratesi CA, Marino M, Principato L, Vannuzzi E. Working toward Healthy and Sustainable Diets: The "Double Pyramid Model" Developed by the Barilla Center for Food and Nutrition to Raise Awareness about the Environmental and Nutritional Impact of Foods. Front Nutr. 2015;2:9-9. doi: 10.3389/fnut.2015.00009

67. Moresi M. Assessment of the life cycle greenhouse gas emissions in the food industry. Agro Food Ind Hi Tec. 2014;25(3):53-62. doi:

68. Bowman SA. A methodology to price foods consumed: development of a food price database. Fam Econ Nutr Rev. 1997;10(1):26-31. doi:

69. Gazan R, Barré T, Perignon M, Maillot M, Darmon N, Vieux F. A methodology to compile food metrics related to diet sustainability into a single food database: Application to the French case. Food Chem. 2018;238:125-133. doi: 10.1016/j.foodchem.2016.11.083

70. Seconda L, Baudry J, Allès B, et al. Comparing nutritional, economic, and environmental performances of diets according to their levels of greenhouse gas emissions. Clim Change. 2018;148(1):155-172. doi: 10.1007/s10584-018-2195-1

71. Donati M, Menozzi D, Zighetti C, Rosi A, Zinetti A, Scazzina F. Towards a sustainable diet combining economic, environmental and nutritional objectives. Appetite. 2016;106:48-57. doi: 10.1016/j.appet.2016.02.151

72. Seconda L, Baudry J, Allès B, et al. Assessment of the Sustainability of the Mediterranean Diet Combined with Organic Food Consumption: An Individual Behaviour Approach. Nutrients. 2017;9(1):61. doi: 10.3390/nu9010061

73. Conway GR. Agroecosystem analysis. Agric Admin. 1985;20(1):31-55. doi: 10.1016/0309-586X(85)90064-0

74. Gerber M, Hoffman R. The Mediterranean diet: health, science and society. Br J Nutr. 2015;113 Suppl 2:S4-10. doi: 10.1017/s0007114514003912

75. Grosso G. The Mediterranean diet as a sustainable dietetic model. Eur J Public Health. 2018;28(suppl_4).doi: 10.1093/eurpub/cky213.765

76. Serra-Majem L, Bach-Faig A, Miranda G, Clapes-Badrinas C. Foreword: Mediterranean diet and climatic change. Public Health Nutr. 2011;14(12a):2271-2273. doi: $10.1017 / \mathrm{s} 1368980011002503$ 
77. United Nations Educational Scientific and Cultural Organization. Representative List of the Intangible Cultural Heritage of Humanity. 2019; https://ich.unesco.org/en/lists. Accessed December 13, 2019.

78. Azzini E, Maiani G, Turrini A, et al. The health-nutrition dimension: a methodological approach to assess the nutritional sustainability of typical agro-food products and the Mediterranean diet. J Sci Food Agric. 2018;98(10):3684-3705. doi: 10.1002/jsfa.8877

79. Annunziata A, Agovino M, Mariani A. Sustainability of Italian families' food practices: Mediterranean diet adherence combined with organic and local food consumption. $J$ Clean Prod. 2019;206:86-96. doi: 10.1016/j.jclepro.2018.09.155

80. Prosperi P, Allen T, Padilla M, Peri I, Cogill B. Sustainability and Food \& Nutrition Security: A Vulnerability Assessment Framework for the Mediterranean Region. SAGE Open. 2014;4(2):2158244014539169. doi: 10.1177/2158244014539169

81. Rose D, Heller MC, Roberto CA. Position of the Society for Nutrition Education and Behavior: The Importance of Including Environmental Sustainability in Dietary Guidance. J Nutr Educ Behav. 2019;51(1):3-15.e11. doi: 10.1016/j.jneb.2018.07.006

82. Dernini S, Berry EM, Serra-Majem L, et al. Med Diet 4.0: the Mediterranean diet with four sustainable benefits. Public Health Nutr. 2017;20(7):1322-1330. doi: $10.1017 / \mathrm{s} 1368980016003177$ 